\title{
英文報告
}

\section{Executive Director's Annual Report, 2007}

\section{Sadamichi ASHINA}

The Fifty-fourth Academic Conference of The Japan Society of Christian Studies was held at Sophia University, on September 21-22, 2006. The national board of directors and the general meeting were, also, held, where the officers of the Society were changed; the previous officers were Dr. Seiichi Yagi (Toin University of Yokohama), president; Prof. Yoshinobu Tobo (Aoyama Gakuin University), executive director; Dr. Koichi Namiki (International Christian University), editor of Theological Studies in Japan. The new officers are Dr. Wataru Mizugaki (Kyoto University), president; Associate Prof. Sadamichi Ashina (Kyoto University), executive director; Prof. Eiichi Katayanagi (Kyoto University), editor. The secretariat is at Kyoto University. Prof. Makoto Mizutani (Doshisha University) and Prof. Kenji Doi (Kwansei Gakuin University) are secretaries.

The new secretariat has decided to pay particular attention to the following two topics: 1) information technology and 2) international exchange. Through the laudable efforts of the previous secretariat, mountains of paper-based data have been digitized, thereby significantly enhancing office efficiency. The society also now has its own website, which greatly increases its public exposure and accessibility. We hope to continue development of this new medium.

In the area of international exchange, the society is happy to report that many of its members participated in the recent 2006 Japan-Korea Theology Forum held on November 24-25 of last year. This forum focused on developing a new Asian theology that would be able to act to reconcile, and that goes beyond nationalism in both countries. Synthesizing a new paradigm that leads to mutual understanding and that focuses on commonalities rather than differences is a high priority for our Society.

The keynote address of this Fifty-Forth Academic Conference was entitled "Theology and its Role in Christianity and Higher Education in Japan in the 21 st 
Century" and was delivered by Dr. Hans-Jurgen Marx of Nanzan University. Professor Marx lucidly enumerated the active contributions which the field of theology is naturally suited to make in both the Church and academia. A brief list of these contributions includes 1) the search for truth, 2) the cultivation of ethics and 3) addressing the notion of relativism. The symposium of the conference was titled "Church, Theology and Biblical Studies" and featured panelists Dr. Shunichi Takayanagi, emeritus professor of Sophia University, as Chair; Dr. Tomoaki Fukai of Seigakuin University who spoke on the topic of theology as it relates to the Church; Dr. Tetsuo Yamaga of Hokusei Gakuin University who spoke from the viewpoint of Old Testament studies and Dr. Takashi Onuki of Tokyo University who spoke from the viewpoint of New Testament Studies. The symposium's theme is very timely and is highly relevant to our Society's mission of contributing to the public discourse on the role of theology in the Japanese Church. We look forward to further opportunities to facilitate similar dialogues on this matter.

Twenty-four individual research papers were given in simultaneous sessions at this year's conference with lively debate on each proposed theory. Subjects included the Old Testament, New Testament, church history, systematic theology and modern theological problems.

The branch chapters of the Society were reported as follows. In the Kanto meeting, held on March 16 at Rikkyo University, six scholars gave papers followed by a main lecture and three presentations for the open symposium on the theme "Suffering of people and Asian Theology." The Kyushu Meeting held on March 27 at Seinan Gakuin University included five presentations and a public lecture by Prof. Yoshinori Inagaki (Nagasaki Junshin Catholic University) on the theme of "Holy Mother in the theology of Thomas Aquinas." At Kinki meeting held at Kobe College on March 29, eighteen scholars gave papers in four simultaneous sessions followed by a public lecture on the theme of "The possibility of theological Studies in Japan" by Dr. Seiichi Yagi.

The Tohoku meeting held at Tohoku Gakuin University on June 16 included five presentations and a public lecture by Prof. Katsuhiko Kondo (Tokyo Union Theological Seminary) on the theme of "The doctrine of Atonement as a constitutive principle of Christian identity." In the Hokkaido meeting held on June 
30 at Hokkaigakuen University, two scholars gave papers in a public symposium on the theme of "Rethinking the Christian Studies." 